\title{
PENGETAHUAN MAHASISWA KEPERAWATAN TENTANG SASARAN KESELAMATAN PASIEN
}

\author{
Undergraduate Nursing Students Knowledge about Patient Safety Goals
}

\author{
Aprilia Nuryanti ${ }^{1}$ \\ ${ }^{1}$ Sekolah Tinggi Ilmu Kesehatan Dirgahayu Samarinda \\ email: aprilnuryanti@gmail.com
}

\begin{abstract}
ABSTRAK
Pendahuluan: Tuntutan masyarakat saat ini terhadap kepuasan layanan dan keselamatan pasien selama dirawat menjadi tantangan besar bagi dunia keperawatan. Mahasiswa harus dibekali dengan pengetahuan, sikap dan keterampilan yang memadai dalam melaksanakan program sasaran keselamatan pasien (SKP). Tujuan penelitian ini adalah mengevaluasi pengetahuan dan pengalaman belajar mahasiswa terhadap SKP. Metodologi: Penelitian deskriptif yang dilakukan terhadap 71 mahasiswa tingkat II yang telah mendapatkan mata kuliah pasient safety yang dipilih dengan teknik convenient sampling. Kuesioner digunakan untuk mengukur tingkat pengetahuan tentang SKP. FGD dilakukan kepada 7 partisipan untuk menggali pengalaman belajar di kelas dan laboratorium. Hasil: Rata-rata pengetahuan mahasiswa tentang SKP adalah cukup (53,5\%). Tingkat pengetahuan baik pada SKP 4 dan tingkat pengetahuan cukup pada 5 SKP lainnya. Tema-tema yang ditemukan dalam FGD adalah ruang lingkup keselamatan pasien, pihak yang bertanggung jawab dan tugasnya dalam sasaran keselamatan pasien dan upaya melaksanakan sasaran keselamatan pasien. Diskusi: Institusi pendidikan perlu mengembangkan capaian pembelajaran SKP dengan metode praktikum dan menyesuaikan perkembangan instrumen SKP di wahana praktik.
\end{abstract}

Kata Kunci : pengetahuan, sasaran keselamatan pasien, mahasiswa keperawatan

\section{ABSTRACT}

Background: The people's demands for service satisfaction and patient safety during care were a major challenge for the world of nursing. Students must be equipped with adequate knowledge, attitudes and skills in implementing the patient safety goals program. The purpose of this study was evaluate the knowledge and learning experience of students towards Patient Safety Goals (PSG). Method: Descriptive research was conducted on 71 level II students who had obtained patient safety subject chosen by convenient sampling technique. The questionnaire was used to measure the level of knowledge about PSG. The FGD was conducted on 7 participants to explore lecture in class and laboratory practice experiences. Result: Student knowledge about patient safety goals rated category fairly by 53,5\% of the samples. Good level of knowledge on patient safety goals 4 and sufficient level in five other PSG. The themes found in the FGD were the scope of patient safety, the parties responsible and duties in the patient safety goals and effort to implement patient safety goals. Discussion: Educational institutions need to develop PSG learning outcomes with laboratory practice methods and adjust the development of PSG instruments in practical area.

Keywords: knowledge, patient safety goals, nursing students

\section{PENDAHULUAN}

Keselamatan pasien di rumah sakit adalah salah satu bentuk pelayanan kesehatan yang aman dan tidak merugikan pasien. Seluruh komponen pelayanan kesehatan (dokter, perawat dan tim kesehatan lainnya) di rumah sakit harus sadar dan peduli terhadap keselamatan pasien selama berada di rumah sakit (Setiowati, 2010).

Joint Comission International (JCI) telah menetapkan sasaran keselamatan pasien di rumah sakit (National Patient Safety Goals/ NPSG) untuk meningkatkan keselamatan pasien, yaitu 1) Identifikasi pasien dengan benar; 2) Meningkatkan komunikasi efektif; 3)
Menggunakan obat yang aman; 4) Kepastian tepat lokasi, tepat prosedur dan tepat pasien; 5) Menurunkan risiko infeksi terkait pelayanan kesehatan dan 6) Mengidentifikasi risiko jatuh pada pasien. JCI merilis NPSGs baru yang efektif pada bulan Januari 2018; meliputi Improve the accuracy of patient and resident identification; Improve the safety of using medications; Reduce the risk of health careassociated infections; Reduce the risk of patient and resident harm resulting from falls; Prevent health care-associated pressure ulcers (decubitus ulcers) (JCI, 2017).

Kelalaian individu merupakan ancaman terjadinya kejadian yang tidak diharapkan 
pada pasien. Institute Medicine of America melaporkan 100.000 orang meninggal setiap tahun sebagai akibat dari kesalahan medis, kesalahan berasal berasal dari efek samping obat, komplikasi bedah, kesalahan sistem, dan kesalahan pengobatan. Studi di Kanada didapatkan $7-12 \%$ pasien di rumah sakit mengalami efek samping obat dan 30-40\% dari peristiwa itu dapat dicegah. Berdasarkan laporan tersebut maka penting untuk meningkatkan program keselamatan pasien (Forster, A.J., Dervin, G., Martin Jr., C., Papp, S., 2012); (Montoya, I.D., Kimbal, O.M., 2013). Mahasiswa keperawatan yang sedang melaksanakan praktik terdapat kemungkinan melakukan suatu kesalahan di rumah sakit. Faktor individu berpengaruh terhadap kualitas perawatan dan keselamatan pasien salah satunya adalah mahasiswa (Mwachofi, A., Walston, S.L., \& Al-Omar, B., 2011).

Akademi Keperawatan Dirgahayu Samarinda merupakan institusi pendidikan tinggi yang menghasilkan lulusan Perawat Vokasional, memiliki sikap dan kemampuan dalam bidang keperawatan yang diperoleh melalui penerapan Kurikulum Pendidikan. Pengalaman belajar mahasiswa meliputi pengalaman belajar di kelas, laboratorium, klinik, dan lapangan, dilengkapi dengan fasilitas belajar yang menunjang tercapainya kemampuan yang harus dimiliki. Dalam hubungannya dengan praktik klinik keperawatan, mahasiswa menggunakan rumah sakit, puskesmas, rumah sakit jiwa, panti sosial tresna werdha dan masyarakat sebagai wahana dalam pencapaian kompetensinya.

Tuntutan masyarakat saat ini terhadap kepuasan layanan dan keselamatan pasien selama dirawat menjadi tantangan besar bagi dunia keperawatan pada umumnya. Mahasiswa harus dibekali dengan pengetahuan, sikap dan keterampilan yang memadai dalam melaksanakan program pendukung hal tersebut, salah satunya melaksanakan program sasaran keselamatan pasien (SKP). Oleh karena itu, sudah seharusnya institusi pendidikan memberikan materi yang relevan dengan program tersebut sehingga mahasiswa telah kompeten dalam program sasaran keselamatan pasien di RS.

Kurikulum pendidikan diploma 3 keperawatan salah satu mata kuliah yang harus ditempuh mahasiswa adalah Manajemen Patient Safety yang terletak pada struktur kurikulum semester 4 (tingkat 2). Penelitian ini dilakukan untuk mendapatkan gambaran tingkat pengetahuan dan pengalaman belajar mahasiswa secara lebih fokus terhadap bagian dari topik "Sasaran Keselamatan Pasien" mata kuliah Manajemen Patient Safety. Hasil penelitian dapat dimanfaatkan untuk melakukan pengembangan topik pembelajaran pada kurikulum mata kuliah Manajemen Patient Safety yang membantu mahasiswa untuk menerapkan program SKP ini ketika mereka sedang belajar praktik klinik keperawatan di wahana praktik.

\section{METODE}

Penelitian ini menggunakan rancangan deskriptif. Proses penelitian dimulai dengan menelaah fakta dan melihat kebutuhan pengembangan pembelajaran di institusi. Selanjutnya, menetapkan subyek penelitian, mengumpulkan data, menganalisa data secara deskriptif dan melaporkan hasil.

Populasi mahasiswa tingkat 2 adalah sebanyak 132 orang. Teknik sampling yang digunakan adalah convenient sampling pada populasi mahasiswa tingkat 2 di Akademi Keperawatan Dirgahayu Samarinda. Subyek penelitian sebanyak 71 orang mahasiswa. Focus Group Discussion dilakukan dengan tujuh partisipan yang dipilih dengan teknik sampling purposive. Variabel tunggal dalam penelitian ini adalah pengetahuan tentang sasaran keselamatan pasien.

Pengumpulan data dilakukan dengan metode diskusi kelompok terarah dan dengan kuisioner. FGD dilakukan menggunakan panduan pertanyaan, selama FGD direkam dengan alat perekam. Kuisioner tentang tingkat pengetahuan SKP berjumlah 24 butir soal berupa pernyataan dengan jawaban skala nominal (benar atau salah). Setiap sasaran keselamatan pasien diwakili dengan empat (4) soal. Hasil uji reliabilitas dengan Alpha Cronbach item soal menunjukkan reliabilitas keseluruhan yaitu $0.398>\mathrm{R}$ tabel. Seluruh soal dalam kategori reliable. Uji validitas dengan Pearson Product Moment Correlation menunjukkan seluruh item soal valid $(>\mathrm{R}$ tabel).

Data yang terkumpul dilakukan analisa secara deskriptif sebagi berikut: pengetahuan baik (76-100), cukup (60-75) dan buruk (<60). Hasil dari diskusi kelompok terarah akan ditelaah dan ditambahkan untuk menggali data kualitatif tentang persepsi mahasiswa tentang SKP dan harapan terhadap metode belajar pada mata kuliah Patient Safety. 
Lokasi penelitian adalah di Akademi Keperawatan Dirgahayu Samarinda, di Jalan Pasundan No. 21 Kelurahan Jawa dan di kampus Akper Dirgahayu Jl. Gunung Merbabu No.68 Kelurahan Jawa, Kota Samarinda. Penelitian dilakukan mulai bulan Mei sampai Desember 2017.

\section{HASIL DAN PEMBAHASAN \\ HASIL \\ Pengetahuan dan Persepsi Mahasiswa tentang Sasaran Keselamatan Pasien}

Data demografi responden penelitian didapatkan dari kuisioner yang diisi oleh responden. Tabel 1 menggambarkan data demografi. Sebagian besar responden berjenis kelamin perempuan, dengan rentang usia 1920 tahun. Persentase terbesar indeks prestasi kumulatif (IPK) pada rentang 3,00-3,49. Responden adalah mahasiswa yang mendapat nilai MK Manajemen Patient Safety tanpa remidi.

Tabel 1. Karakteristik responden penelitian

\begin{tabular}{lcc}
\hline Karakteristik & Frekuensi & Persentase \\
\hline 1. Jenis Kelamin & & \\
a. Laki-laki & 16 & 22,54 \\
b. Perempuan & 55 & 77,46 \\
Total & 71 & 100 \\
\hline 2. Umur & & \\
a. $17-18$ & 5 & 7,04 \\
b. $19-20$ & 56 & 78,87 \\
c. $>20$ tahun & 10 & 14,09 \\
Total & 71 & 100 \\
\hline 3. IPK & & \\
a. 2,00-2,49 & 5 & 7,04 \\
b. 2,50-2,99 & 27 & 38,02 \\
c. 3,00-3,49 & 30 & 42,25 \\
d. 3,50-4,00 & 9 & 12,69 \\
Total & 71 & 100 \\
\hline Sumber: data prim
\end{tabular}

Sumber: data primer, 2017

\section{Tabel 2. Pengetahuan mahasiswa tentang sasaran keselamatan pasien $(\mathbf{N}=\mathbf{7 1})$}

Sumber: data primer

Sebagian besar mahasiswa memiliki pengetahuan cukup (69) tentang SKP. Ratarata pengetahuan mahasiswa tingkat II tentang SKP adalah 69 (minimum 50 dan maksimum 91,7).

Tabel 3. Rata-rata pengetahuan mahasiswa pada komponen SKP $(\mathrm{N}=71)$

\begin{tabular}{lcc}
\hline \multicolumn{1}{c}{ Komponen SKP } & Nilai & Kategori \\
\hline $\begin{array}{l}\text { Ketepatan Identifikasi Pasien } \\
\text { (SKP 1) }\end{array}$ & 68,67 & Cukup \\
\hline $\begin{array}{l}\text { Peningkatan Komunikasi Efektif } \\
\text { (SKP 2) }\end{array}$ & 63,03 & Cukup \\
\hline Peningkatan kepada Obat-obatan & 71,48 & Cukup \\
\hline
\end{tabular}

yang perlu diwaspadai (SKP 3)

Ketepatan prosedur, tepat pasien $\quad 84,16 \quad$ Baik

dan tepat lokasi (SKP 4)

Penurunan Risiko Infeksi terkait $\quad 62,68 \quad$ Cukup

Pelayanan Kesehatan (SKP5)

\begin{tabular}{lll}
\hline Penurunan Risiko Jatuh (SKP 6) & 60,21 & Cukup \\
\hline
\end{tabular}

Sumber: Data Primer, 2017

Rata-rata komponen dalam SKP yang paling baik adalah ketepatan prosedur, tepat pasien dan tepat lokasi (SKP 4). Nilai rata-rata paling rendah pada SKP 6. Mahasiswa kurang tepat mengidentifikasi warna gelang risiko jatuh pada pasien berisiko. Penurunan risiko infeksi terbatas pada cuci tangan prinsip benar (SKP 5). Pengetahuan tentang legalitas komunikasi lisan melalui telepon ketika menerima instruksi belum lengkap (SKP 2). Identifikasi pasien kurang tepat karena dipahami dengan data nama dan nomor tempat tidur (SKP 1).

Diskusi kelompok terarah dilakukan untuk menjawab daftar pertanyaan yang berhubungan dengan topik SKP, pentingnya bagi mahasiswa dan harapan mahasiswa terhadap mata kuliah ini. Dalam diskusi digali sejauh mana pemahaman mahasiswa dalam penerapan SKP dan pentingnya bagi keselamatan pasien. Pertanyaan pertama adalah tentang apa yang dipahami mahasiswa tentang sasaran keselamatan pasien.

Sasaran keselamatan pasien adalah standar pelayanan kesehatan untuk menjauhkan cedera (partisipan 5)

Prosedur mencegah atau mengurangi cedera fisik pada pasien (partisipan 3)

Tindakan pencegahan untuk melindungi terjadinya kecelakaan, cidera untuk pasien, keluarga dan tenaga medis (partisipan 1)

\begin{tabular}{lcc}
\hline $\begin{array}{l}\text { Kategori } \\
\text { Pengetahuan }\end{array}$ & Frekuensi & Persentase \\
\hline Buruk & 11 & 15,5 \\
Cukup & 49 & 69,0 \\
Baik & 11 & 15,5 \\
Total & $\mathbf{7 1}$ & $\mathbf{1 0 0}$ \\
\hline
\end{tabular}

Pendapat ketiga partisipan mendefinisikan sasaran keselamatan pasien sebagai standar, prosedur dan tindakan. Tujuan dari SKP adalah menjauhkan, mencegah, mengurangi cedera pada pasien, keluarga, termasuk pada tenaga kesehatan yang bekerja.

Komponen yang ada dalam SKP yang disebutkan oleh beberapa partisipan adalah 
cuci tangan, alat pelindung diri, pagar pada tempat tidur, infeksi nosokomial, risiko jatuh, label obat, pembatasan pengunjung, benar obat, pencahayaan, kenyamanan pasien, tata letak ruangan, letak WC, pegangan pasien, penggunaan lift untuk pasien khusus (pasien dengan penyakit jantung, stroke, fraktur) untuk mencegah jatuh.

Tanggung jawab semua.... Tenaga medis, dokter, analis, petugas laborat, cleaning service, pasien, keluarga. Manajemen, bidang keselamatan kerja untuk mengontrol dan mengawasi pelaksanaan, menyediakan alat, fasilitas. Humas melakukan sosialisasi pada petugas, pasien dan keluarga (partisipan 1)

Hasil diskusi menggambarkan partisipan yang menjawab memahami pihak-pihak yang bertanggung jawab pada SKP. Penyebutan batasan tugas masing-masing pihak disebutkan dengan benar sesuai dengan tujuan SKP.

Sebagai perawat, pelaksanaan SKP dilakukan untuk seluruh tindakan. Parapartisipan menyebutkan hal-hal yang harus dilakukan adalah dalam pemberian obat, orientasi lingkungan RS, pemberian bantuan perawatan ADL pasien, penggunaan gelang identitas pasien, label obat LASA (look alike sound alike), label risiko jatuh, alergi.

Membantu pasien sesuai kebutuhan dasar $A D L$, memeriksa tingkat kesadaran pasien, atau pasien yang fraktur, lansia dan anakanak perlu diawasi dan dipasang gelang kuning (partisipan 2)

Evaluasi pembelajaran mata kuliah Patient Safety disebutkan partisipan dalam beberapa topik seperti diungkapkan berikut

Yang berkesan itu.... Prakteknya
(partisipan 6)

Kalau gaya belajar yang sesuai dengan saya itu ya diskusi, praktek atau role play (partisipan 4)

Ceramah di awal, maju menjelaskan per individu, terus demonstrasi atau role play .... Jadi lebih mengena, lebih masuk (partisipan 3)

Harapannya, dosen menanyakan pada mahasiswa mau belajar dengan metode apa, jadi negosiasi dulu (partisipan 3)
Seluruh partisipan menyebutkan "praktek" sebagai metode pembelajaran yang paling disukai dan dinilai menarik.

\section{PEMBAHASAN}

Hasil penelitian menunjukkan kesamaan pada komponen ketepatan prosedur, tepat pasien dan tepat lokasi dengan penelitian Pratama dan Nurmalia (2016) yang menunjukkan pengetahuan mahasiswa dengan persentasi baik (74\%). Hal ini mungkin disebabkan lingkup ketepatan prosedur, lokasi dan pasien adalah terbatas pada materi prosedur operasi sehingga mahasiswa mempunyai persepsi yang tepat dan lebih mudah dipahami. Penelitian Muharam, dkk (2013) menunjukkan implementasi baik pada sasaran ketepatan identifikasi pasien $(69,3 \%)$, komunikasi efektif $(53,3 \%)$, keamanan obat $(58,7 \%)$, pengurangan risiko infeksi $(68,0 \%)$, dan pengurangan risiko pasien jatuh $(54,7 \%)$. Penelitian lain melaporkan ketepatan identifikasi pasien (69,3\%), komunikasi efektif $(53,3 \%)$, keamanan obat $(58,7 \%)$, pengurangan risiko infeksi $(68,0 \%)$, dan pengurangan risiko pasien jatuh $(54,7 \%)$. Hasil ini sesuai dengan hasil penelitian bahwa pengurangan risiko jatuh mendapatkan presentase keberhasilan yang paling buruk.

Peraturan Menteri Kesehatan Nomor 11 Tahun 2011 tentang Keselamatan Pasien mencantumkan pembentukan sistem pelayanan yang menjamin asuhan pasien lebih aman, melalui upaya yang meliputi asesmen risiko, identifikasi dan pengelolaan risiko pasien. Dalam kurikulum diploma III keperawatan perlu capaian pembelajaran yang diintegrasikan dengan tuntutan RS dan wahana praktik lain. Rumitnya instrumen risiko jatuh yang berbeda-beda menurut kelompok usia (bayi/ anak, dewasa dan lansia) menyebabkan mahasiswa kurang menguasai pengkajian. Ditambah dengan berbagai alat untuk peningkatan kewaspadaan jatuh seperti gelang, tanda bahaya, pagar pengaman, penggunaan alas kaki yang tepat, lantai yang tidak licin, pencahayaan dan lain-lain menuntut mahasiswa memiliki pengetahuan yang cukup luas. Hal-hal ini mahasiswa kurang menguasai seluruh komponen lengkap tentang pencegahan pasien jatuh.

Diskusi kelompok terarah dengan mahasiswa menghasilkan tema-tema sebagai berikut

1. Ruang lingkup keselamatan pasien 
2. Pihak yang bertanggung jawab dan tugasnya dalam sasaran keselamatan pasien

3. Upaya melaksanakan sasaran keselamatan pasien

Ruang lingkup sasaran keselamatan pasien menurut partisipan adalah prosedur, standar pelayanan dan tindakan pencegahan menjauhkan, mencegah dan mengurangi cedera pada pasien, keluarga dan tenaga medis. Peraturan Menteri Kesehatan Nomor 11 Tahun 2011 tentang Keselamatan Pasien menyebutkan bahwa keselamatan pasien adalah suatu sistem yang bertujuan agar asuhan pada pasien lebih aman untuk meminimalkan munculnya risiko dan mencegah cedera yang diakibatkan oleh kesalahan atau kelalaian dari tindakan yang dilakukan.

Pihak yang bertanggungjawab dalam mewujudkan keselamatan pasien meliputi seluruh komponen di rumah sakit. Partisipan menyebutkan pihak manajemen selaku pengambil kebijakan, pengatur dan pengawas, seluruh tenaga medis yang bekerja di RS termasuk tenaga penunjang seperti cleaning service. Pihak yang menjadi sasaran program adalah pasien dan keluarga. Peraturan Menteri Kesehatan Nomor 11 Tahun 2011 menyebut penyelenggaran keselamatan pasien dilakukan dengan membentuk sistem pelayanan yang mengaplikasikan 1) standar keselamatan pasien, 2) sasaran keselamatan pasien dan 3) tujuh langkah menuju keselamatan pasien. Sistem tersebut mengatur pemberian asuhan langsung yang dilakukan oleh petugas medis, pelaporan insiden dan implementasi manajemen risiko cedera. Berdasar uraian tersebut, hasil diskusi menggambarkan pemahaman yang baik dari mahasiswa tentang pihak yang terlibat dan bertanggungjawab pada keselamatan pasien. Partisipan dapat menyebutkan contoh tugas dari parapihak. Tuntutan akreditasi Komisi Akreditasi Rumah Sakit (KARS) saat ini menuntut mahasiswa yang sedang praktik klinik di RS mengikuti standar keselamatan pasien sama seperti yang dilakukan oleh petugas medis.

Upaya melaksanakan sasaran keselamatan pasien yang disebutkan parapartisipan meliputi pelaksanaan cuci tangan, penggunaan alat pelindung diri, pagar pada tempat tidur, pencegahan infeksi nosokomial, penurunan risiko jatuh, menempelan label obat, pembatasan pengunjung, benar obat, pencahayaan, kenyamanan pasien, pengaturan tata letak ruangan, letak WC, pegangan pasien, penggunaan lift untuk pasien khusus (pasien dengan penyakit jantung, stroke, fraktur) untuk mencegah jatuh. Penyelenggaraan keselamtan pasien dalam Peraturan Menteri Kesehatan Nomor 11 Tahun 2011 meliputi Sasaran Keselamatan Pasien yaitu 1) mengidentifikasi pasien dengan benar; 2) meningkatkan komunikasi yang efektif; 3) meningkatkan keamanan obat-obatan yang harus diwaspadai; 4) memastikan lokasi pembedahan yang benar, prosedur yang benar, pembedahan pada pasienyang benar; 5) mengurangi risiko infeksi akibat perawatan kesehatan; 6) mengurangi risiko cedera pasien akibat terjatuh.

Berdasarkan hasil diskusi mahasiswa telah menyebutkan penyelenggaraan namun belum mengelompokkan klasifikasi SKP. Penyelenggaraan SKP 1 yang disebutkan adalah penggunaan gelang identitas pasien. SKP 2 tidak disebutkan sama sekali. SKP 3 disebutkan secara lengkap meliputi label obat LASA (look alike sound alike), menempelan label obat, label alergi pada pasien dan prinsip pemberian benar obat. SKP 4 tidak disebutkan pelaksanaannya. SKP 5 cukup banyak disebut pelaksanannya yaitu pelaksanaan cuci tangan, penggunaan alat pelindung diri, pencegahan infeksi nosokomial, pembatasan pengunjung. SKP 6 paling banyak dijelaskan partisipan yaitu penggunaan label risiko jatuh, penggunaan pagar pada tempat tidur, penurunan risiko jatuh, pencahayaan, kenyamanan pasien, pengaturan tata letak ruangan, letak WC, pegangan pasien, penggunaan lift untuk pasien khusus (pasien dengan penyakit jantung, stroke, fraktur) untuk mencegah jatuh.

Hasil jawaban partisipan dalam diskusi ada yang tidak mendukung hasil analisa deskriptif kuisioner pada SKP 4. Pengetahuan dalam kategori baik, namun dalam diskusi justru tidak disebutkan lingkup pelaksanaan sasaran keselamatan pasien. Hal ini dimungkinkan karena mahasiswa belum pernah praktik klinik di lingkungan kamar operasi sehingga belum memiliki pengalaman dalam hal ketepatan identifikasi pasien, prosedur dan lokasi pembedahan meskipun secara teori mereka lebih baik dalam pemahamannya.

Metode belajar yang diharapkan mahasiswa dalam mata kuliah Patient Safety adalah praktikum dalam bentuk praktek di laboratorium dan role play. Peran pembimbing pada saat praktik klinik mempunyai hubungan yang bermakna dalam pelaksanaan keselamatan pasien yang dilaksanakan oleh 
mahasiswa (Suryani, L., Handiyani, H., \& Hastono S.P., 2015). Hasil penelitian yang menemukan fakta bahwa mahasiswa lebih memilih belajar praktikum karena ketika metode tersebut dilakukan rasio pembimbing dan mahasiswa kecil sehingga pembimbingan lebih intens. Mahasiswa dapat mencoba melakukan Pratik langsung, tidak hanya duduk, mendengar dan mencatat.

\section{KESIMPULAN DAN SARAN}

Rata-rata pengetahuan mahasiswa tentang sasaran keselamatan pasien adalah cukup. Pengetahuan tentang SKP 1, 2, 3, 5 dan 6 dalam kategori cukup; SKP 4 dalam kategori baik. Ruang lingkup keselamatan pasien, pihak-pihak yang bertanggungjawab dan upaya melaksanakan sasaran keselamatan pasien dijelaskan mahasiswa dengan baik meskipun masih ada ruang lingkup yang tidak dijelaskan yaitu SKP 4.

Saran bagi institusi pendidikan adalah mengembangkan capaian pembelajaran pada mata kuliah Patient Safety agar memperhatikan juga tuntutan akreditasi pelayanan kesehatan di wahana praktik, menggiatkan aktivitas praktikum, menyediakan peralatan yang semirip mungkin dengan wahana praktik (misalnya tanda bahaya jatuh, mengatur setting laboratorium yang mencerminkan pencegahan jatuh seperti jenis lantai, pengaturan tata letak, menyediakan gelang/ label pasien jatuh, pintu kamar mandi membuka ke arah luar, dll.). Jika diperlukan dapat mengundang perawat pendidik dari wahana praktik sebagai dosen tamu dalam mata kuliah Patient Safety atau Manajemen Keperawatan agar mengetahui perkembangan tuntutan akreditasi tempat pelayanan kesehatan terkait dengan SKP.

\section{KEPUSTAKAAN}

Forster, A.J., Dervin, G., Martin Jr., C., Papp, S, 2012. Improving patient safety through the systematic evaluation of pastient outcomes. Canadian Journal of Surgery, 55(6), 418-425.

JCI, 2017. Nursing Care Center: 2018. National Patient Safety Goals, (Online), (https://www.jointcommission.org/assets/1/ 6/NPSG_Chapter_NCC_Jan2018.pdf., diakses tanggal 5 Agustus 2017, jam 12.05 WITA).
Kementrian Kesehatan Republik Indonesia, 2011. Peraturan Menteri Kesehatan Republik Indonesia Nomor 11 Tahun 2017 tentang Keselamatan Pasien, (Online), (https://jdih.baliprov.go.id/uploads/produkhukum/peraturan/2017/PERMENKES/per menkes-11-2017.pdf, diakses 10 Agustus 2017, jam 13.00 WITA).

Montoya, I.D., Kimbal, O.M., 2013. Gauging Patient Safety Program. Journal of Allied Health, 42(3).

Muharram, Framika; Rivai, Fridawaty; Mangilep, Adelia U. Ady, 2016. Gambaran Implementasi Sasaran Keselamatan Pasien oleh Perawat di Ruang Rawat Inap Rumah Sakit Universitas Hasanuddin. Skripsi, (Online),

(http://repository.unhas.ac.id/handle/12345 6789/18933, diakses 3 Agustus 2017, jam 15.00 WITA).

Mwachofi, A., Walston, S.L., \& Al-Omar, B., 2011. Factors affecting nurses' perceptions of patient safety. International Journal of Health Care Quality Assurance, 24(4); 274283.

Pratama, A.R \& D. Nurmalia, 2016. Gambaran Kompetensi Mahasiswa Keperawatan terhadap Pelaksanaan Sasaran Keselamatan Pasien di RSUD Ungaran Kabupaten Semarang. Undip reposiroty, (Online), (http://eprints.undip.ac.id/49202/, diakses 3 Agustus 2017, jam 14.00 WITA).

Setiowati, D., 2010. Hubungan Kepemimpinan Efektif Head Nurse dengan Penerapan Budaya Keselamatan Pasien oleh Perawat Pelaksana di RSUPN Dr. Cipto Mangunkusumo Jakarta. Tesis. Universitas Indonesia.

Suryani, L., Handiyani, H., \& Hastono S.P., 2015. Peningkatan Pelaksanaan Keselamatan Pasien oleh Mahasiswa oleh Peran Pembimbing Klinik. Jurnal Keperawatan Indonesia, 18(2), 115-122. 